\title{
HUMAN ENDOMETRIAL ADENOCARCINOMA: GROWTH HORMONE INVOLVEMENT IN CANCER CHEMORESISTANCE
}

\author{
Erica Gentilin, Carmelina Di Pasquale, Katiuscia Benfini, Simona Falletta, Eleonora Riva, \\ Ettore degli Uberti, Maria Chiara Zatelli
}

Section of Endocrinology and Internal Medicine, Dept. of Medical Sciences, University of Ferrara, Italy

\section{OBJECTIVES}

Endometrial cancer is the most frequent malignancy of the female genital tract, the fifth leading cause of cancer-related death in women. The influence of the growth hormone $(\mathrm{GH})$ /insulin like growth factor on cell growth regulation has been recently the focus of much interest. Experimental data support the hypothesis that $\mathrm{GH}$ may influence neoplastic development of several tissues, among them endometrial epithelium. Indeed, $\mathrm{GH}$ is produced by normal and neoplastic endometrial cells and is capable to increase the oncogenicity of EA cells by an autocrine mechanism (1). Endometrial epithelium of patients with EA show high GH levels (2) and EA is one of the most occurring tumors in acromegalic patients (3). We previously established that $\mathrm{GH}$ has a protective action towards the cytotoxic effects of doxorubicin chemotherapeutic agent $(4,5)$, suggesting that $\mathrm{GH}$ excess may have an important role in cancer escape from therapy. This evidence prompted us to investigate whether $\mathrm{GH}$ might influence the development of chemoresistance to drugs routinely employed in EA treatment.

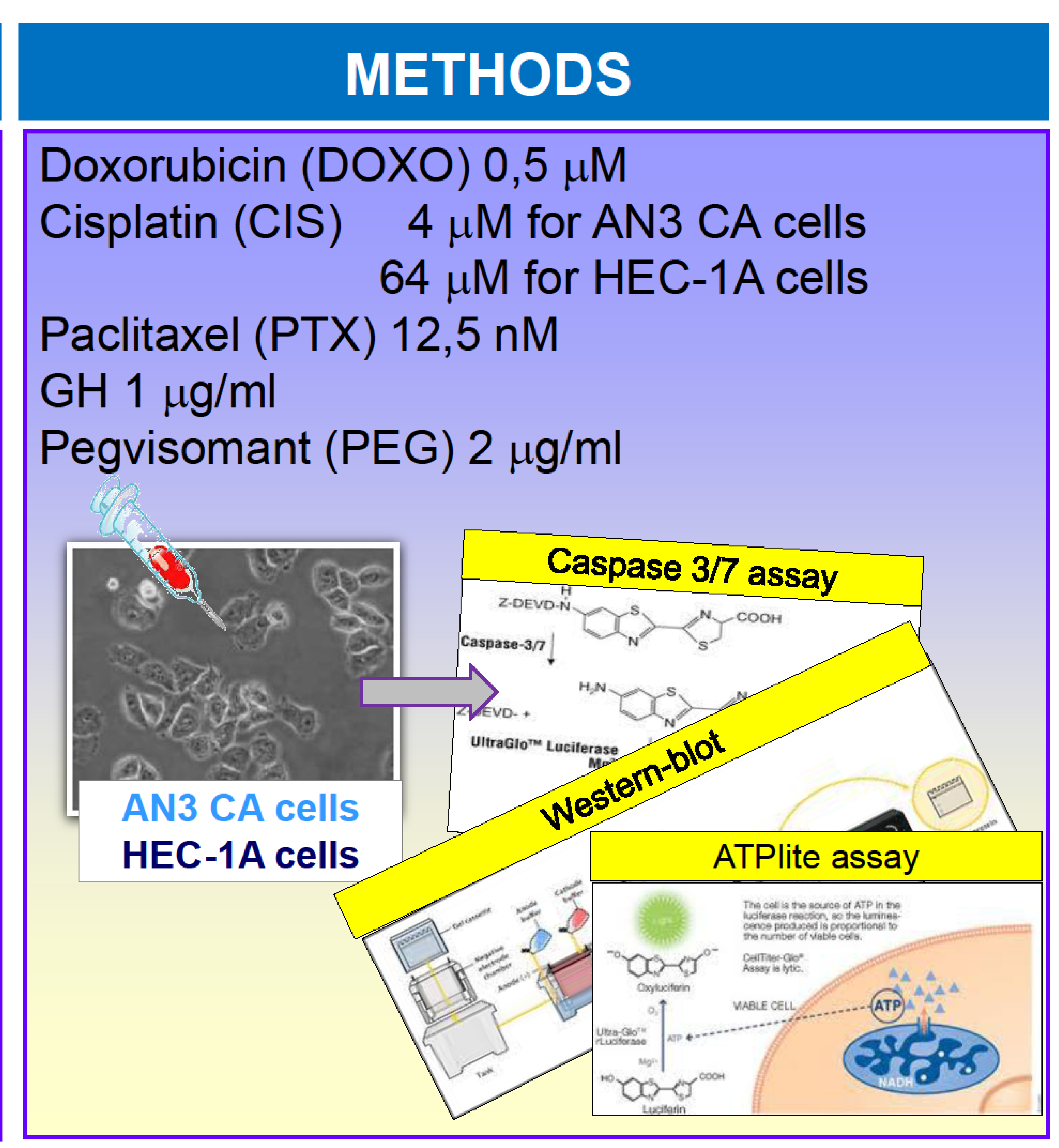

\section{RESULTS}
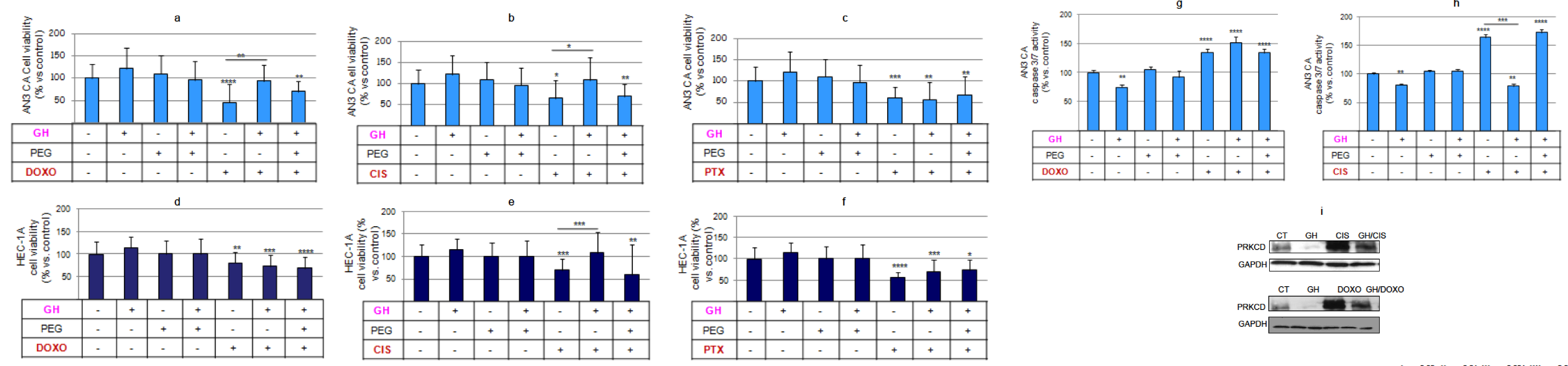

As shown in the figures $a, b$ and $c$, all the chemotherapy drugs tested significantly reduced AN3 CA cell viability. GH blunted the inhibitory effects of DOXO and CIS on cell viability, but did not influence PTX effects. On the other hand, PEG, a GH receptor antagonist, completely abolished GH effects. Concerning HEC-1A cells, as shown in figures d, e and $\mathrm{f}$, all the drug tested significantly reduced cell viability. GH did not influence the inhibitory effects of DOXO and PTX on cell viability, but blunted CIS effects. The latter phenomenon was completely abolished by PEG. Since HEC-1A demonstrated scant sensitivity to the effects of $\mathrm{GH}$, we performed the other experiments only in the AN3 CA cell line. As shown in figures $\mathrm{g}$ and $\mathrm{h}, \mathrm{GH}$ significantly reduced caspase $3 / 7$, while DOXO and CIS significantly induced it. GH did not influence the stimulatory effects of DOXO, but is capable to blunt the stimulatory effects of CIS; a phenomenon abolished by PEG. As shown in figure i, GH reduced PRKCD protein levels; on the contrary DOXO and $\mathrm{CIS}$ induced PRKCD expression, an effect blunted by $\mathrm{GH}$ treatment.

\section{CONCLUSIONS}

These results show that $\mathrm{GH}$ is capable of rescuing EA cells from both the inhibitory effects of DOXO on cell viability and the effects of CIS on cell vaibility and caspase activation. Moreover, these results suggest that $\mathrm{GH}$ may contribute to EA chemoresistance by PRKCD inhibition. This may provide new insights on novel therapies against EA chemoresistant aggressive tumors.

\section{References}

1)Pandey V et al. Endocrinology 2008; 149:390919

2) Slater M et al. Acta Histochem. 2006; 108:13-8 3) Bałdys-Waligórska A et al. Endokrynol Pol. 2010; 61:29-34

4) Zatelli MC et al. J Clin Endocrinol Metab 2009; 94:3931-8 